Como se observa, esta pequena molécula, cuja ausência tantos problemas provocou nas viagens marítimas, é essencial para a conservação dos alimentos e para a nossa saúde. Através do consumo de alimentos frescos e ricos nesta molécula, nomeadamente morangos, laranjas, frutos tropicais, bróculos, pimentos, cajús, salsa, espinafres, entre outros, estamos a contribuir para melhorar as condições da viagem que é a vida, que se quer longa. Mas sempre condimentada pela presença da Química...entre nós.

\section{Saiba mais em:}

Autoridade de Segurança Alimentar e Económica, Aditivos alimentares, asae.gov. $\mathrm{pt} / \mathrm{seguranca-alimentar/aditivos-alimentares/antioxidantes.aspx} \mathrm{(acedido} \mathrm{em}$ 11/06/2021).

Sapo Lifestyle, lifestyle.sapo.pt/saude/noticias-saude/artigos/500-anos-depoiso-escorbuto-esta-de-volta-a-culpa-e-das-dietas-pouco-variadas (acedido em $11 / 06 / 2021)$

Café com química, Química da Vitamina C, youtube.com/watch?v=cD6yRNujKoQ (acedido em 11/06/2021).

World of molecules, Vitamin CMolecule, worldofmolecules.com/antioxidants/ vitaminc.htm (acedido em 11/06/2021).

S. Murad D. Grove, K. A. Lindber G. Reynolds, A Sivarajah, S. R. Pinnell, Proc Natl. Acad. Sci. USA 1981, 78, 2879-2882. DOI: 10.1073/pnas.78.5.2879.

Luís de Camões, Os Lusíadas, Livraria Civilização Editora, Barcelos, 1999.

\title{
À Procura das \\ Especiarias: o Cravinho
}

\section{Marta Piñeiro}

mpineiro@qui.uc.pt

Conta a história que a luta pelo controlo do comércio de especiarias foi a grande motivação impulsionadora da viagem de circum-navegação de Fernão de MagaIhães. No século XV, o comércio das especiarias era dominado por mercadores de Génova e Veneza. As especiarias, vindas do Oriente pelo mar Mediterrâneo, eram vendidas a preço de ouro nas cidades europeias. Entre as mais importantes, destacavam-se a pimenta, a canela, o gengibre, a noz-moscada e o cravinho. Na época dos Descobrimentos, em particular com a descoberta do caminho marítimo para a Índia pelo navegador Vasco da Gama, Portugal consolidou o domínio das rotas comerciais. As especiarias, raras e caras, eram bens valiosos chegando a valer mais do que o ouro. A comercialização destes bens preciosos, entre outros, possibilitou o financiamento necessário a Portugal para a epopeia dos Descobrimentos.

Segundo L. F. F. R. Thomaz no seu livro O Drama de Magalhães e a Volta ao Mundo sem Querer, o cravinho, hoje comparado ao café (que, depois do petróleo, é a segunda mercadoria do comércio internacional), era das especiarias mais caras (mais do que a pimenta e o gengibre) no século XVI, sendo consumido na Pérsia, China e Índia. 0 cravinho, também conhecido por cravo-da-índia, é o botão floral seco de uma árvore (Syzygium aromaticum), originária das ilhas Molucas (atualmente parte da Indonésia), que pode atingir os 8 a 10 m de altura. Para além da sua utilização

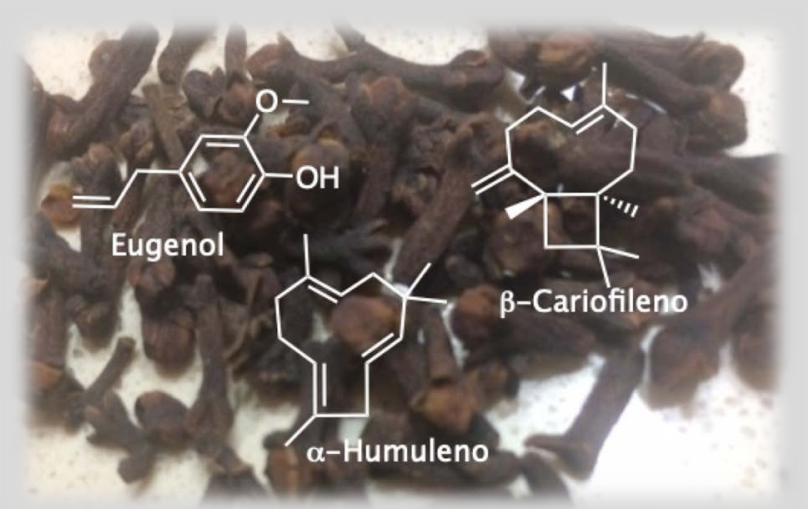

como tempero, o cravinho também era utilizado para evitar infestações de formigas, e o seu óleo tem diversas aplicações terapêuticas relacionadas com os seus diversos componentes.

A composição do óleo de cravinho, que pode ser obtido por destilação simples, por arraste de vapor ou por extração com solventes (também utilizando dióxido de carbono supercrítico, $\mathrm{scCO}_{2}$ ), depende da origem, da preparação e da forma de extração, mas apresenta sempre o mesmo componente principal, o eugenol (4-alil-2-metoxifenol), em proporções entre $70-90 \%$. É a este composto que se associa o aroma característico do cravinho e várias das suas propriedades terapêuticas. Dos botões secos extrai-se 15-20\% de óleo essencial, sendo a maior parte eugenol. Um quilograma de cravinho origina aproximadamente $150 \mathrm{~mL}$ de eugenol. $0 \beta$-cariofileno e o $\alpha$-humuleno são dois constituintes minoritários do cravinho. 0 primeiro é responsável pela atividade inseticida do 
cravinho enquanto que o segundo é responsável pelas propriedades anestésicas e anti-inflamatórias. Atualmente, o cravinho continua a ser produzido principalmente na Indonésia, em Madagáscar e na Tanzânia, continuando a ser um dos produtos com maior valor comercial a nível mundial.

\section{Saiba mais em:}

R. S. Affonso, M. N Rennó, G. B. C. A. Slana, T. C. C. França, Rev. Virtual Quim 2012, 4, 146-161. DOI: 10.5935/1984-6835.20120012.

B. Kabak, A. D. W. Dobson, Crit. Rev. Food. Sci. Nutrit. 2017, 57, 18-34. DOI: 10.1080/10408398.2013.772891.

RTP Ensina, Na Rota das Especiarias, ensina.rtp.pt/artigo/na-rota-dasespeciarias (acedido em 11/06/2021).

L. F. F. R. Thomaz, O Drama de Magalhães e a Volta ao Mundo sem Querer, Gradiva, 2019, ISBN: 9789896168599.

\section{Mar Salgado}

A água cobre a maior parte da superfície do nosso planeta. Dos 1386 milhões de quilómetros cúbicos de água na superfície terrestre apenas 2,5\% são de água doce, ou seja, aproximadamente 1351 milhões de quilómetros cúbicos são água salgada. Os mares e oceanos sulcados por Fernão de Magalhães na viagem de circum-navegação são grandes massas de água salgada! São soluções de volume gigantesco de compostos químicos!

A salinidade resulta da quantidade total de sólidos inorgânicos dissolvidos na água. Dos sais inorgânicos dissolvidos em mares e oceanos, a grande maioria (80-85\%) é cloreto de sódio ( $\mathrm{NaCl}$, comummente conhecido por sal ou sal de cozinha devido à sua utilização universal como tempero), 14-19\% correspondem a sulfato de cálcio $\left(\mathrm{CaSO}_{4}\right)$, sulfato de magnésio $\left(\mathrm{MgSO}_{4}\right)$ e cloreto de magnésio $\left(\mathrm{MgCl}_{2}\right)$ e o restante $(1 \%)$ a uma infinidade de outros sais. A quantidade de sais na água do mar é influenciada pelo clima. A temperatura e a pluviosidade são fatores determinantes e, portanto, a salinidade do mar varia em função da região. Considera-se que a salinidade normal corresponde a 35 g/L (35 gramas de sal para cada litro de água). Por exemplo, o mar Báltico, situado entre a península da Escandinávia e a Europa

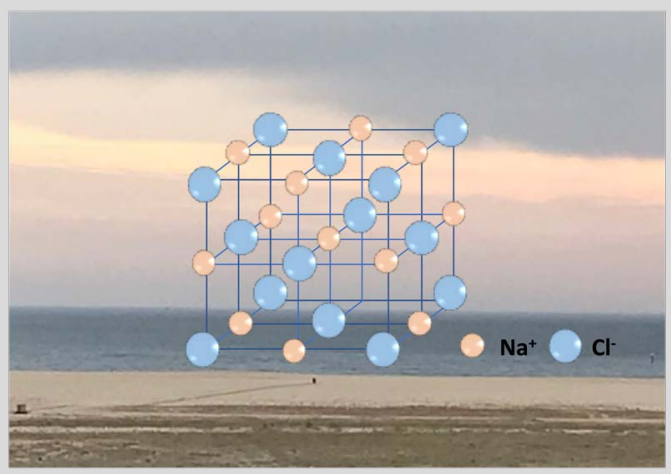
Marta Piñeiro

mpineiro@qui.uc.pt

continental, possui $30 \mathrm{~g} / \mathrm{L}$ de sal e o mar Vermelho, um golfo do oceano Índico entre África e a Ásia, 40 g/L. Já no mar Morto, um lago salgado que banha Israel, a Cisjordânia e a Jordânia, o teor de sais é de $300 \mathrm{~g} / \mathrm{L}$, o que praticamente impossibilita a existência de vida aquática, daí a sua designação.

No mar e nos oceanos há triliões de toneladas de sal! Aliás, uma das formas de produzir este apreciado tempero, potenciador do sabor das refeições, é a evaporação natural da água do mar, realizada em salinas costeiras e interiores. Em Portugal, de norte a sul, há uma longa tradição de extração do sal do mar que nos banha para a produção de sal marinho. o "sal marinho" difere do "sal de mesa" ou "sal refinado" por ser obtido diretamente por evaporação da água do mar, em vez da extração em minas de sal e, em consequência, contém outros elementos como magnésio, potássio ou cálcio em pequenas quantidades. Apesar do sal em excesso poder aumentar o risco de várias doenças (a chave está na moderação), a composição mais complexa do sal marinho tem sido associada a benefícios para a saúde humana. No entanto, é muito importante relembrar que para que mantenha essas propriedades, é necessário cuidar dos Mares e dos Oceanos.

\section{Saiba mais em:}

National History Museum, Why is the sea salty?, nhm.ac.uk/discover/quickquestions/why-is-the-sea-salty.html (acedido em 11/06/2021).

Conselho Nacional da Água, Água no Planeta Terra, conselhonacionaldaagua. weebly.com/aacutegua-no-planeta-terra.html (acedido em 11/06/2021).

Projeto Sal Ciência, SPQ, sal.spq.pt (acedido em 11/06/2021).

Geografia e Ecologia das Salinas, sal.spq.pt/docs/Apresentacao\%20Ciencia\%20 viva\%20FINAL.pdf (acedido em 11/06/2021).

American Heart Association, heart.org/en/healthy-living/healthy-eating/eatsmart/sodium/sea-salt-vs-table-salt (acedido em 11/06/2021).

B.-H. Lee, A.-R. Yang, M. Y. Kim, S. McCurdy, W. A. Boisvert, Food Nutr. Res. 2017 61, 1264713. DOI: 10.1080/16546628.2017.1264713. 